\title{
Retrosigmoid transmeatal and suprajugular approach for cerebellopontine angle meningioma: operative video
}

\author{
Ken Matsushima, MD, and Michihiro Kohno, MD, PhD \\ Department of Neurosurgery, Tokyo Medical University, Tokyo, Japan
}

Surgical management of cerebellopontine angle meningiomas is challenging due to the intricate neurovascular structures within the limited operative field and the compression of eloquent structures including the brainstem. Surgery on tumors extending into the temporal bone is especially difficult and demands complicated approaches. However, modifications to the retrosigmoid approach utilizing intradural temporal bone drilling enable access to such tumoral extensions without any additional invasive approaches. This video demonstrates the case of a cerebellopontine angle meningioma extending into the internal acoustic meatus and jugular foramen that was surgically treated through the retrosigmoid transmeatal and suprajugular approaches under continuous vagus nerve monitoring.

The video can be found here: https://youtu.be/aUD1vr6TbOc.

KEYWORDS internal auditory canal; jugular foramen; transmeatal approach; suprajugular approach; skull base surgery

SUBMITTED June 12, 2017. ACCEPTED June 28, 2017.

INCLUDE WHEN CITING Published online October 1, 2017; DOI: http://thejns.org/doi/abs/10.3171/2017.10.FocusVid.17290.

CORRESPONDENCE Michihiro Kohno, Department of Neurosurgery, Tokyo Medical University, No. 6-7-1 Nishishinjuku, Shinjuku-ku, Tokyo 160-0023, Japan.

email: mkouno-nsu@umin.ac.jp. 